\title{
REVIEW
}

Open Access

\section{Does high-grade dysplasia/carcinoma in situ of the biliary duct margin affect the prognosis of extrahepatic cholangiocarcinoma? A meta-analysis}

Qiao Ke ${ }^{1+}$, Bin Wang ${ }^{2,3+}$, Nanping Lin ${ }^{1+}$, Lei Wang ${ }^{1,4^{*}}$ and Jingfeng Liu ${ }^{1,5^{*}}$

\begin{abstract}
Background: High-grade dysplasia/carcinoma in situ (HGD/CIS) of the biliary duct margin was found to not affect the prognosis of patients with extrahepatic cholangiocarcinoma by recent studies, but it has not yet reached a conclusion.

Methods: Eligible studies were searched by PubMed, PMC, MedLine, Embase, the Cochrane Library, and Web of Science, from Jan. 1, 2000 to Jun. 30, 2019, investigating the influences of surgical margin status of biliary duct on the prognosis of patients with resectable extrahepatic cholangiocarcinoma. Overall survival (OS) and local recurrence were evaluated by odds ratio (OR) with 95\% confidence interval (Cl).

Results: A total of 11 studies were enrolled in this meta-analysis, including 1734 patients in the R0 group, 194 patients in the HGD/CIS group, and 229 patients in the invasive carcinoma (INV) group. The pooled OR for the 1-, 2-, and 3-year OS rate between HGD/ClS group and R0 group was 0.98 (95\% Cl 0.65 1.50), 1.01 (95\% Cl 0.73 1.41), and 0.98 (95\% Cl 0.72 1.34), respectively. The pooled OR for the 1-, 2-, and 3-year OS rate between HGD/CIS group and INV group was 1.83 (95\% Cl 1.09 3.06), 4.52 (95\% Cl 2.20 9.26), and 3.74 (95\% Cl 2.34 5.96), respectively. Subgroup analysis of extrahepatic cholangiocarcinoma at early stage showed that the pooled OR for the 1-, 2-, and 3-year OS rate between HGD/ClS group and R0 group was 0.54 (95\% Cl 0.21 1.36), 0.75 (95\% Cl 0.35 1.58), and 0.74 (95\% Cl 0.40 1.37), respectively, and the pooled OR for the 1-, 2-, and 3-year OS rate between HGD/CIS group and INV group was 3.47 (95\% Cl 1.09 11.02), 9.12 (95\% Cl 2.98 27.93), and 9.17 (95\% Cl 2.95 28.55), respectively. However, the pooled OR for the incidence of local recurrence between HGD/CIS group and RO group was 3.54 (95\% Cl 1.66 7.53), and the pooled OR for the incidence of local recurrence between HGD/CIS group and INV group was 0.93 (95\% Cl 0.50 1.74).

Conclusion: With the current data, we concluded that HGD/CIS would increase the risk of local recurrence compared with RO, although it did not affect the prognosis of patients with extrahepatic cholangiocarcinoma regardless of TNM stage. However, the conclusion needs to be furtherly confirmed.
\end{abstract}

Keywords: Extrahepatic cholangiocarcinoma, High-grade dysplasia, Carcinoma in situ, Prognosis, Meta-analysis

\footnotetext{
*Correspondence: wangleiy001@126.com; drjingfeng@126.com

${ }^{+}$Qiao Ke, Bin Wang, and Nanping Lin contributed equally to this work.

'Department of Hepatopancreatobiliary Surgery, Mengchao Hepatobiliary

Hospital of Fujian Medical University, Xihong Road 312, Fuzhou 350025,

Fujian, China

Full list of author information is available at the end of the article
}

(c) The Author(s). 2019 Open Access This article is distributed under the terms of the Creative Commons Attribution 4.0 International License (http://creativecommons.org/licenses/by/4.0/), which permits unrestricted use, distribution, and reproduction in any medium, provided you give appropriate credit to the original author(s) and the source, provide a link to the Creative Commons license, and indicate if changes were made. The Creative Commons Public Domain Dedication waiver (http://creativecommons.org/publicdomain/zero/1.0/) applies to the data made available in this article, unless otherwise stated. 


\section{Introduction}

The incidence of extrahepatic cholangiocarcinoma including hilar and distal cholangiocarcinoma is increasing stably $[1,2]$, but the prognosis is generally poor $[3,4]$. Surgical resection is still the only potential way to achieve a long survival [4-6], although most of the patients have lost the chances of surgery at diagnosis $[7,8]$. However, the 5-year survival rate remains far away from satisfactory even if surgery has been undergone $[5,6]$, partly because radical resection is hard to achieve for extrahepatic cholangiocarcinoma in anatomy $[5,6]$.

Margin status is deemed to be associated with prognosis of extrahepatic cholangiocarcinoma [9-11]. Additional resection and adjuvant treatments are often necessary if surgical margin is positive [12-14], although there is no consensus after $\mathrm{R} 0$ resection to deliver adjuvant treatments for resected bile duct cancer [15]. But, several newly published studies showed that compared with invasive carcinoma (INV), high-grade dysplasia/carcinoma in situ (HGD/CIS) of the biliary duct margin did not affect the prognosis of patients with operable cholangiocarcinoma, and additional resection did not improve the prognosis when the margin was HGD/CIS [12, 16-18]. However, most of the studies were single-center, and the sample size was small. Hence, a meta-analysis was warranted to confirm whether HGD/CIS could affect the prognosis of patients with resectable extrahepatic cholangiocarcinoma.

\section{Material and method}

This study was based on the published reports; hence, the informed consent of the patients and the ethical approval were not required. This meta-analysis was conducted according to the Preferred Reporting Items for Systematic Reviews and Meta-Analyses (PRISMA).

\section{Literature search}

A comprehensive search on the existing published medical literature was conducted by Qiao Ke and Nanping Lin to investigate the influences of surgical margin status of biliary duct on the prognosis of patients with resectable extrahepatic cholangiocarcinoma. English electronic databases such as PubMed, PMC, MedLine, Embase, the Cochrane Library, and Web of Science were used to search the literature from Jan. 1, 2000 to Jun. 30, 2019. Keywords were as follows: ("cholangiocarcinoma" or "extrahepatic cholangiocarcinoma" or "bile duct cancer" or "bile duct carcinoma" or "hilar cholangiocarcinoma" or "perihilar cholangiocarcinoma" or "HCCA" or "PHC" or "Klatskin's tumor" or "distal cholangiocarcinoma") AND ("margin" or "duct margin"). Any potentially eligible studies were then identified manually through the references of the included studies, reviews, letters, and comments.

\section{Selection criteria}

Inclusion criteria are as follows: (i) patients with either hilar or distal cholangiocarcinoma; (ii) margin status was confirmed by either intraoperative frozen pathology or postoperative pathology; (iii) groups must include HGD/CIS group, in which the margin status was either HGD or CIS; (iv) outcomes must include overall survival (OS) rate.

Exclusion criteria are as follows: (i) patients including gallbladder carcinoma; (ii) data on the OS rates was not available; (iii) studies based on overlapping cohorts deriving from the same center.

\section{Intervention}

Major hepatectomy or caudate lobectomy with extrahepatic bile duct resection was generally for hilar cholangiocarcinoma $[8,17]$, and the standard Whipple's procedure for distal cholangiocarcinoma [12]. Of note, regional lymph nodes were dissected in all procedures.

Both distal margin and proximal margin were collected to conduct an intraoperative frozen section examination and were evaluated by at least two pathologists within $30 \mathrm{~min}$ [8]. Additional resection was performed if possible when either distal margin or proximal margin was positive, but it mainly depended on each center [12, 18, 19].

Specially, it was extremely difficult to distinguish between high-grade dysplasia (HGD) and carcinoma in situ (CIS) [20]. Herein, in this study, we classified them into HGD/CIS group.

\section{Endpoints}

Primary endpoints were 1-, 2-, and 3-year survival rates either between HGD/CIS group and R0 group or between HGD/CIS group and INV group. Secondary endpoints were the incidence of local recurrence either between HGD/CIS group and R0 group or between HGD/CIS group and INV group.

\section{Data extraction}

Data such as the author's first name, year of publication, study methods, patient's characteristic, interventions, and outcomes were extracted and assessed by Qiao Ke and Nanping Lin according to the predefined forms. The odd ratios (ORs) of 1-, 2-, and 3-year survival rates were extracted directly from the original data or extracted from the Kaplan-Meier curves according to the methods described in detail by Tierney et al. [21] and Parmar et al. [22]. In case of disagreement, a third investigator, Bin Wang, was intervened to reach a conclusion.

\section{Quality assessment}

The quality of non-randomized studies was assessed by the modified Newcastle-Ottawa Scale (NOS) [23], and 
more than 7 stars were defined as high quality, 4 6 star as medium quality, and $<4$ stars as low quality.

\section{Statistical analysis}

The meta-analysis was registered at http://www.crd.york. ac.uk/PROSPERO/ (Review registry 142411) and was performed using RevMan Version 5.3. The outcomes between HGD/CIS and R0 or invasive carcinoma were evaluated by ORs and 95\% CIs. To choose whether random effects or fixed effects mode, the heterogeneity was assessed by the $\chi^{2}$ test and $I^{2}$ statistics; $P<0.10$ or $I^{2}>$ $50 \%$ were considered as significant heterogeneity. When the hypothesis of homogeneity was rejected, the fixed effects model was used to estimate the case with homogeneity, and the random effects model was used for the cases with significant heterogeneity [24, 25]. Sensitivity analysis was conducted as follows: one study at a time was removed and the remained were re-analyzed to determine whether the results could be affected significantly by single study [26]. Begg's and Egger's tests were used to evaluate publication bias using Stata 14, and "trim and fill" method was conducted to test the influence of publication bias on the overall outcomes if the funnel plots were found asymmetric [26]. $P<0.05$ was considered statistically significant, and all $P$ values were two-tailed.

\section{Results}

\section{Base characteristic of the included studies}

A total of 395 records were identified by Qiao Ke and Nanping Lin, including 391 records through electronic search and four records through manual search. Seventeen records were excluded for duplication by NoteExpress 3.1, and then 345 records were excluded after browsing titles and abstracts. Finally, 22 records were excluded after full-text review for the following reasons: (i) 18 records for unclear grouping; (ii) two records for overlapped cohorts [27, 28]; (iii) one record for mixed gallbladder carcinoma [29]; (iv) one record for review [16]. Hence, 11 records were enrolled into our metaanalysis [12, 17-19, 30-36]. The search strategies and results are shown in Fig. 1.

Totally, 2157 patients including 1734 patients in the R0 group, 194 patients in the HGD/CIS group, and 229 patients in the invasive carcinoma (INV) group were included into this study. The characteristics and baseline demographic data of the patients in each research are listed in Table 1. Of note, almost all of the studies came from Japan and South Korea [12, 17-19, 30, 32-36], and only one came from the USA [31]. The incidences of HGD/CIS and INV ranged from 3.0 to $19.5 \%$ and 3.5 to $18.3 \%$, respectively. A total of 10 studies were scored above 6 by NOS [12, 17-19,30,31,33-36], and only one study was scored 6 [32].

\section{Primary endpoint}

The 1-, 2-, and 3-year survival rates comparing between $\mathrm{HGD} / \mathrm{CIS}$ group and R0 group were evaluated in 11 included studies [12, 17-19, 30-36]. Significant heterogeneities were not observed $\left(I^{2}=12 \%, P=0.33 ; I^{2}=9 \%, P\right.$ $=0.36 ; I^{2}=11 \%, P=0.34$; respectively), and using a fixed model, the pooled OR for the 1-, 2-, and 3-year survival rate between HGD/CIS group and R0 group was 0.98 (95\% CI 0.65 1.50, $P=0.94$, Fig. 2a), 1.01 (95\% CI $0.73 \sim 1.41, P=0.793$, Fig. $2 b)$, and $0.98(95 \% \mathrm{CI}$ $0.72 \sim 1.34, P=0.91$, Fig. 2c), respectively.

The 1-, 2-, and 3-year survival rates comparing between HGD/CIS group and INV group were evaluated in nine included studies [12, 17-19, 30, 32-35]. Significant heterogeneities were not observed in 1-year and 3year survival rates $\left(I^{2}=14 \%, P=0.32 ; I^{2}=27 \%, P=\right.$ 0.20 ; respectively), and using a fixed model, the pooled OR for the 1-year and 3-year survival rates between HGD/CIS group and INV group was 1.83 (95\% CI 1.09 3.06, $P=0.02$, Fig. 3a) and 3.74 (95\% CI 2.34 5.96, $P<0.0001$, Fig. 3c), respectively. A significant heterogeneity was shown in 2-year survival rate $\left(I^{2}=47 \%, P=\right.$ 0.06), and using a random model, the pooled OR was 4.52 (95\% CI 2.20 9.26, $P<0.0001$, Fig. 3b).

\section{Subgroup analysis of extrahepatic cholangiocarcinoma at early stage}

The 1-, 2-, and 3-year survival rates of patients with pNOMO comparing between HGD/CIS group and R0 group were evaluated in four included studies [17-19, 34]. Using a fixed model, the pooled OR for the 1-, 2-, and 3year survival rates between HGD/CIS group and INV group was $0.54(95 \%$ CI $0.21 \sim 1.36, P=0.19$, Table 2$), 0.75$ (95\% CI 0.35 1.58, $P=0.44$, Table 2), and 0.74 (95\% CI $0.40 \sim 1.37, P=0.34$, Table 2 ), respectively.

The 1-, 2-, and 3-year survival rates of patients with pNOMO comparing between HGD/CIS group and INV group were evaluated in four included studies [17-19, 34]. Using a fixed model, the pooled OR for the 1-, 2-, and 3year survival rates between HGD/CIS group and INV group was 3.47 (95\% CI 1.09 11.02, $P=0.03$, Table 2), 9.12 (95\% CI 2.98 27.93, $P<0.001$, Table 2), and 9.17 (95\% CI 2.95 28.55, $P<0.001$, Table 2), respectively.

\section{Secondary endpoints}

The incidences of local recurrence comparing between HGD/CIS group and R0 group were evaluated in four included studies $[17,19,30,33]$. Significant heterogeneities were not observed $\left(I^{2}=0, P=0.55\right)$, and using a fixed model, the pooled OR for the incidence of recurrence between HGD/CIS group and R0 group was 3.54 (95\% CI 1.66 7.53, $P=0.001$, Fig. 4a).

The incidences of local recurrence comparing between HGD/CIS group and INV group were evaluated in five 


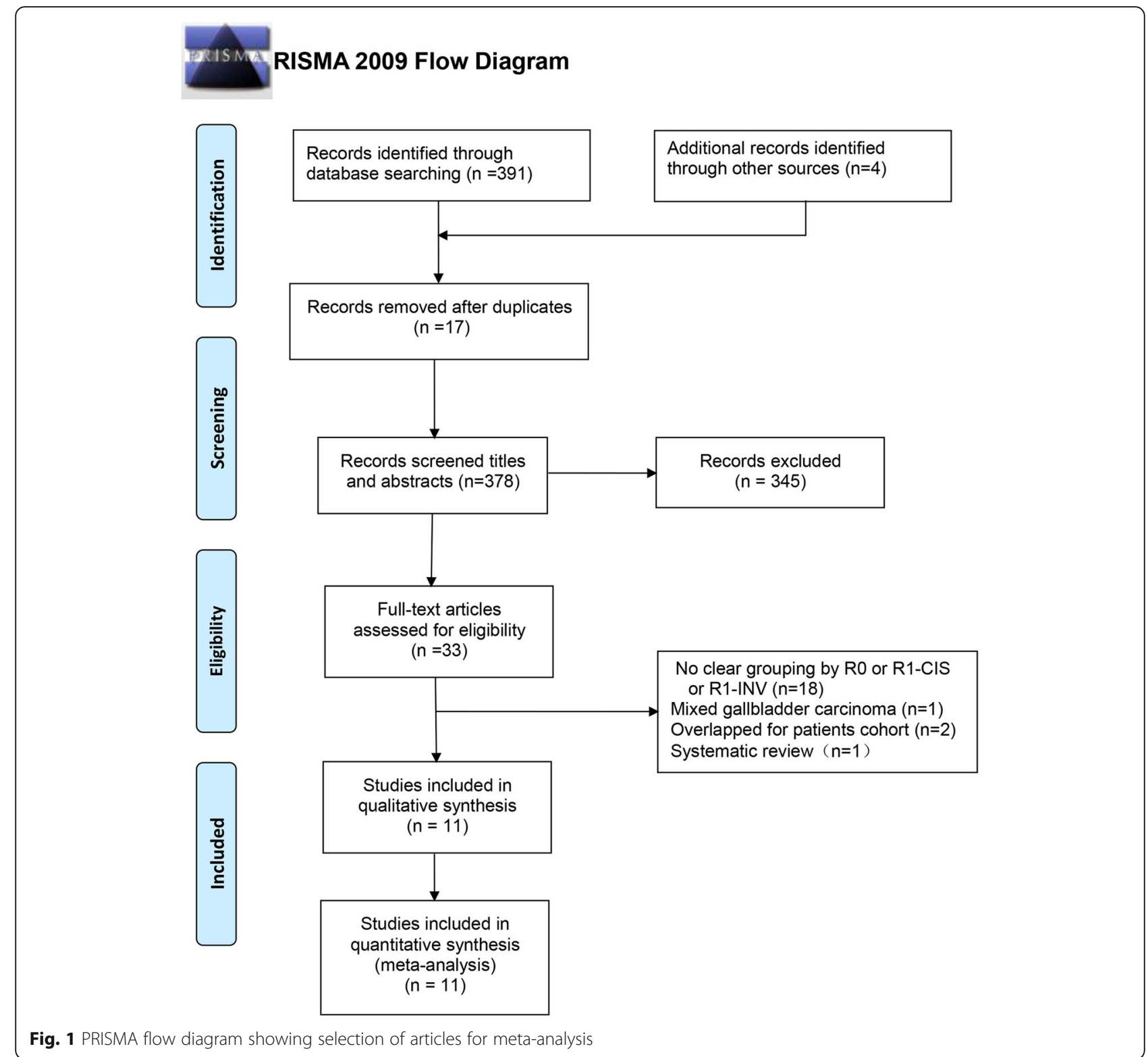

included studies [17, 19, 30, 33, 35]. Significant heterogeneities were not observed $\left(I^{2}=0, P=0.57\right)$, and using a fixed model, the pooled OR for the incidence of recurrence between HGD/CIS group and INV group was 0.93 (95\% CI 0.50 1.74, $P=0.83$, Fig. 4b).

\section{Sensitivity analysis}

Sensitivity analysis showed that both the 1-, 2-, and 3year survival rates comparing between HGD/CIS group and R0 group and the 1-, 2-, and 3-year survival rates comparing between HGD/CIS group and INV group did not change substantially after any study was removed (Fig. 5), which indicated that the results were considerably reliable.

\section{Meta-analysis of baseline characteristics related to prognosis}

Baseline characteristics related to prognosis including the proportion of adjuvant therapy, differentiation, venous invasion, perineural invasion, $\mathrm{pT} 3 / 4$, and $\mathrm{pN} 1 / 2$ were assessed by meta-analysis, and no significant differences were observed both between HGD/CIS group and R0 group and between HGD/CIS group and INV group (Table 3), which indicated that our results were reliable.

\section{Publication bias analysis}

The publication bias analysis was conducted both the 1-, 2, and 3-year survival rates comparing between HGD/ CIS group and R0 group and the 1-, 2-, and 3-year survival rates comparing between $\mathrm{HGD} / \mathrm{CIS}$ group and INV 


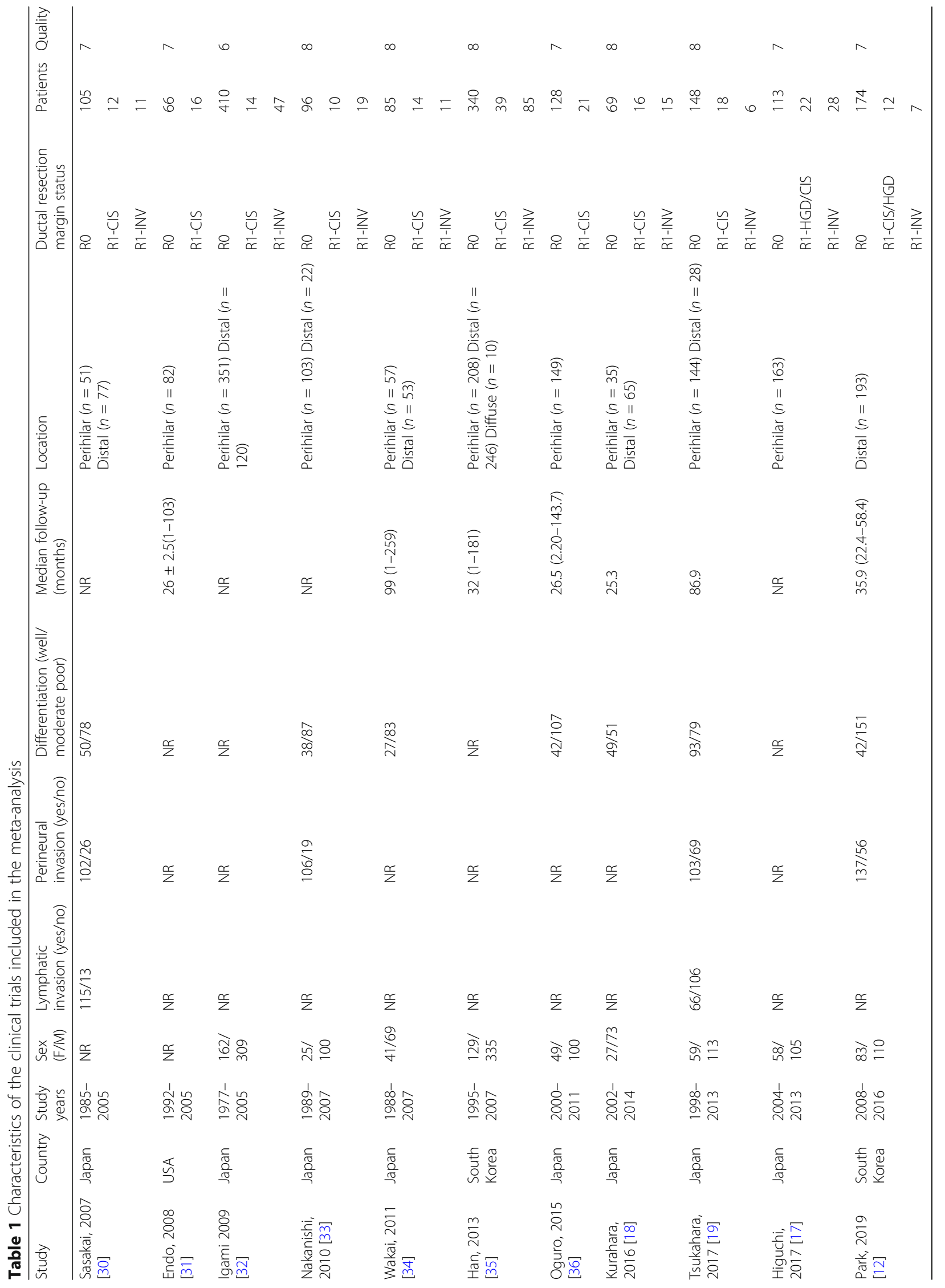




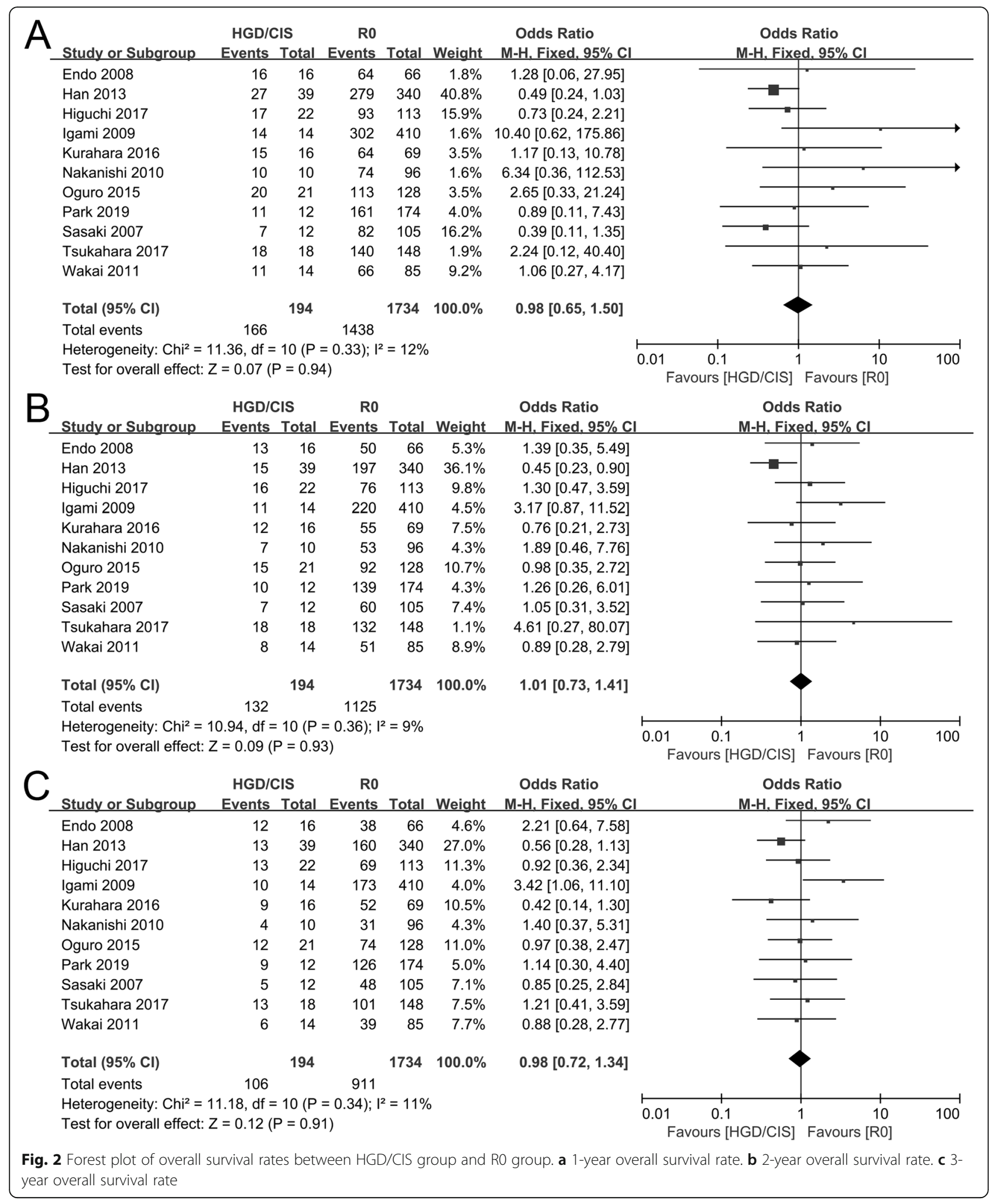

group, and results showed that significant publication bias was not observed in the Begg's test $(\operatorname{Pr}>|z|=$ $0.062,0.087,0.161$, and $\operatorname{Pr}>|z|=0.175,0.175,0.466$; respectively). But, in the egger's test, significant publication bias was observed in the 1- and 2-year survival rates comparing between HGD/CIS group and R0 group and the 2- and 3-year survival rates comparing between HGD/CIS group and INV group $(\operatorname{Pr}>|z|=0.002,0.002$, 


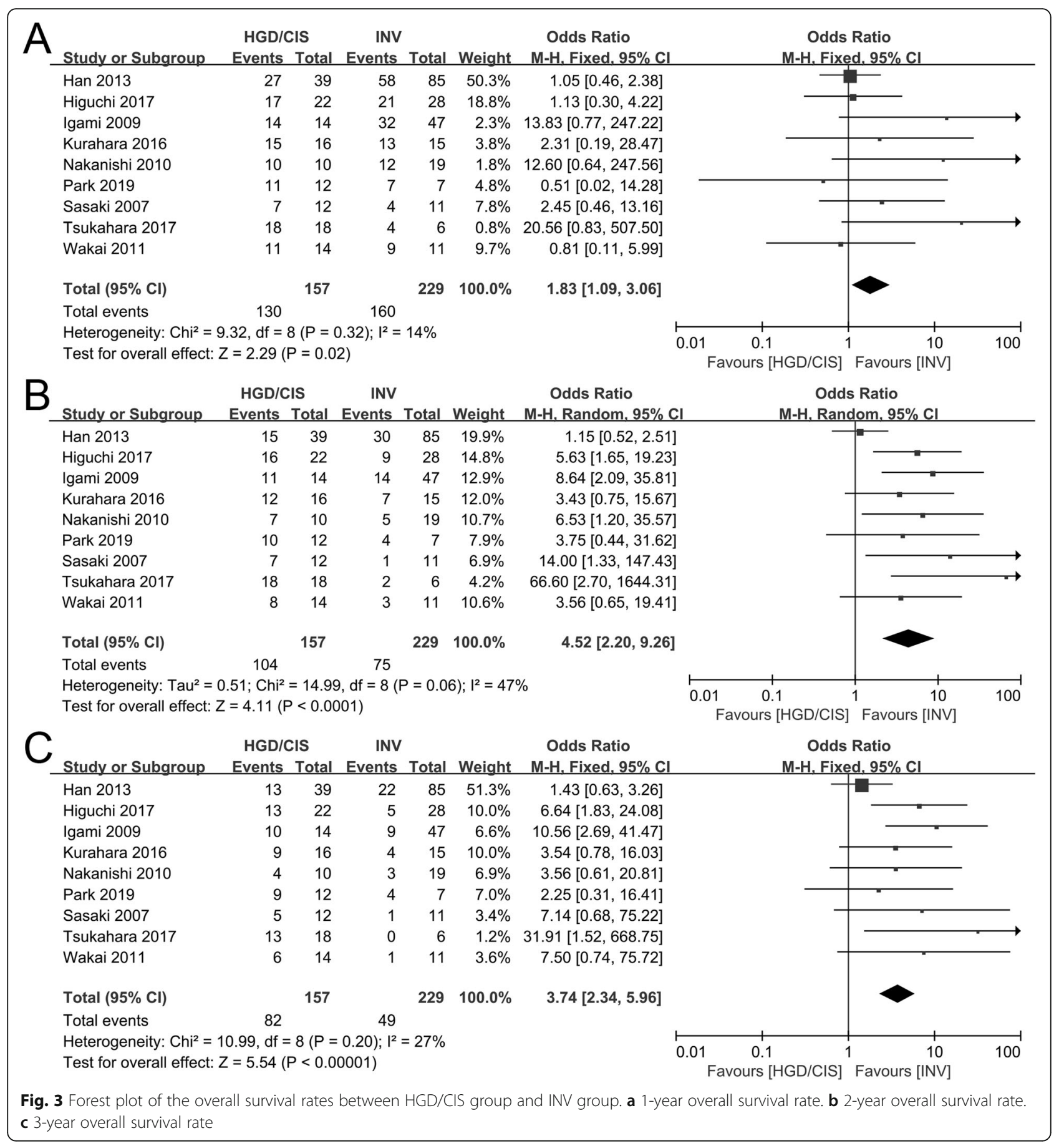

and $\operatorname{Pr}>|z|=0.004,0.044$; respectively), and no significant publication bias was observed in the 3-year survival rates comparing between HGD/CIS group and R0 group and the 1-year survival rates comparing between HGD/ CIS group and INV group $(\operatorname{Pr}>|z|=0.074$, and $\operatorname{Pr}>|z|$ $=0.058$, respectively). After "trim and fill" analysis, the pooled HR for the 1- and 2-year survival rates comparing between HGD/CIS group and R0 group and the 2and 3-year survival rates comparing between HGD/CIS group and INV group was 0.635 (0.363-1.112), 0.750 (0.501-1.124), and 2.368 (1.548-3.622), 2.505 (1.6093.900); respectively, which indicated that the unpublished studies would not change the results.

\section{Discussion}

Surgical resection is still the only potentially curative treatment for patients with extrahepatic cholangiocarcinoma [7, 8], but the incidence of $\mathrm{R} 1$ remains high, 
Table 2 Subgroup analysis of the prognosis of extrahepatic cholangiocarcinoma at early stage

\begin{tabular}{|c|c|c|c|c|c|}
\hline \multirow[t]{2}{*}{ Subgroup } & \multirow{2}{*}{$\begin{array}{l}\text { Studies } \\
\text { included }\end{array}$} & \multicolumn{4}{|c|}{ Overall survival } \\
\hline & & Participants & Effect model & OR $(95 \% \mathrm{Cl})$ & $P$ \\
\hline \multicolumn{6}{|c|}{ pNOMO, HGD/CIS vs. RO } \\
\hline 1 year & 4 & 354 & Fixed & $0.54(0.21-1.36)$ & 0.19 \\
\hline 2 years & 4 & 354 & Fixed & $0.75(0.35-1.58)$ & 0.44 \\
\hline 3 years & 4 & 354 & Fixed & $0.74(0.40-1.37)$ & 0.34 \\
\hline \multicolumn{6}{|c|}{ pNOMO, HGD/CIS vs. INV } \\
\hline 1 year & 4 & 85 & Fixed & $3.47(1.09-11.02)$ & 0.03 \\
\hline 2 years & 4 & 85 & Fixed & $9.12(2.98-27.93)$ & $<0.001$ \\
\hline 3 years & 4 & 85 & Fixed & $9.17(2.95-28.55)$ & $<0.001$ \\
\hline
\end{tabular}

$P$ value is statistically significant

which might be the crucial reason for poorer prognosis $[10,11]$. However, several recent studies found that HGD/CIS did not affect the prognosis of patients with extrahepatic cholangiocarcinoma [12, 16-18], but it has not yet reached a conclusion. To the best of our knowledge, this was the first meta-analysis evaluating the prognostic value of HGD/CIS for extrahepatic cholangiocarcinoma. Results including 11 studies with 2157 patients showed that 1-, 2-, and 3-year survival rates in the group of HGD/CIS were comparable with that in the group of R0, but were better than in the group of INV. However, the incidence of local recurrence in the HGD/CIS group was comparable with INV group, but was significantly higher than that in the R0 group.
R0 resection is a standard procedure for resectable extrahepatic cholangiocarcinoma $[4,37]$, but the incidence of $\mathrm{R} 1$ remains as high as $10 \sim 72 \%[27,38]$. Reasons are as follows: (1) the extent of cholangiocarcinoma infiltration is hard to diagnose preoperatively [8]; (2) complex anatomy of extrahepatic bile duct often increases the risk of surgery in technique [6]; (3) negative false incidence of intraoperative frozen section remains high [39, 40]. HGD/CIS and INV are both defined as R1 [16, 20, 41], but some argues that they might have different outcomes $[12,17,18]$. As known to all, INV is much more aggressive than HGD/CIS in pathology, and it often takes a long time to progress to INV from HGD/CIS [35]. In this meta-analysis, the incidence of R0, HGD/ CIS, and INV was 69.3 90.2\%, 3.0 19.5\%, and

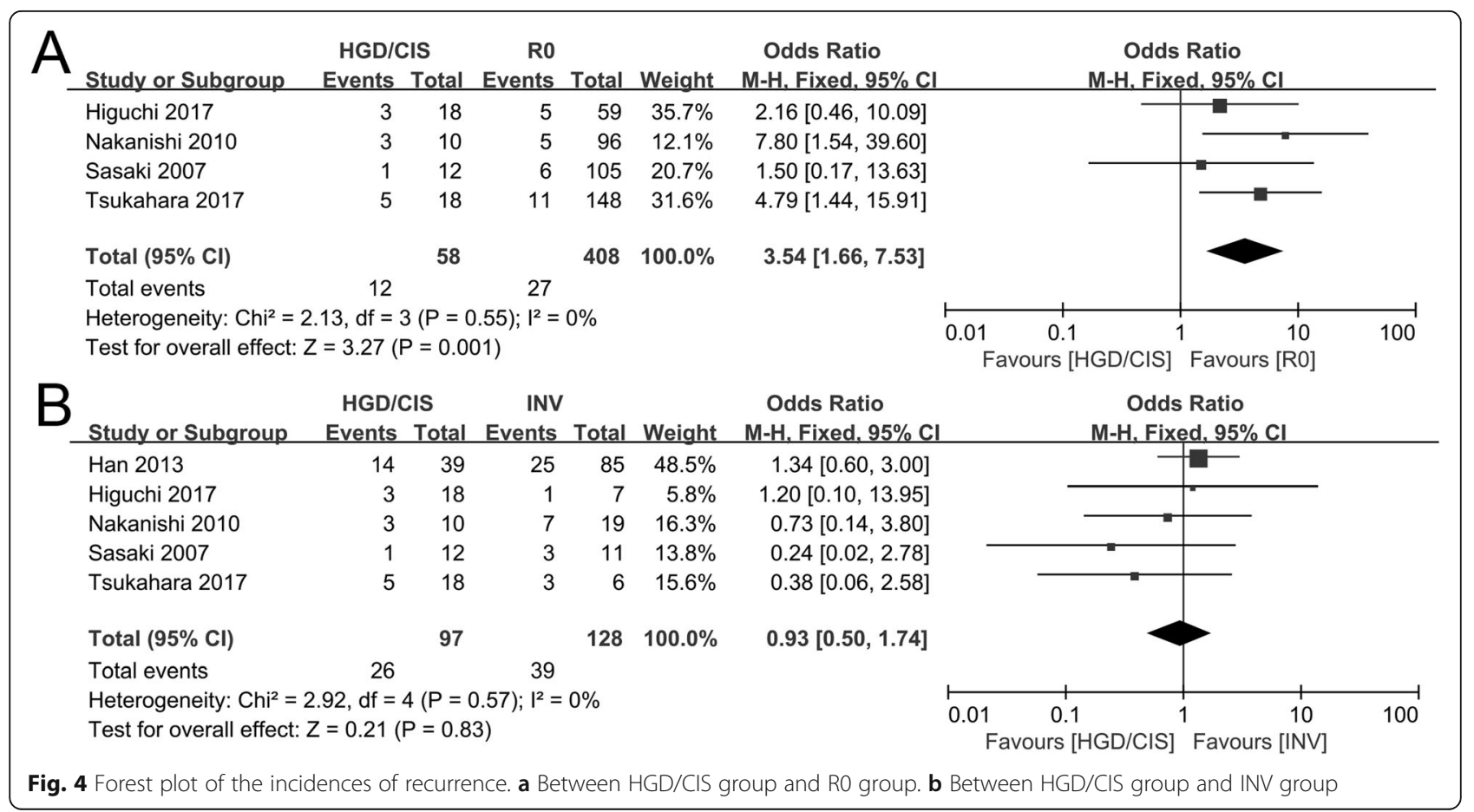




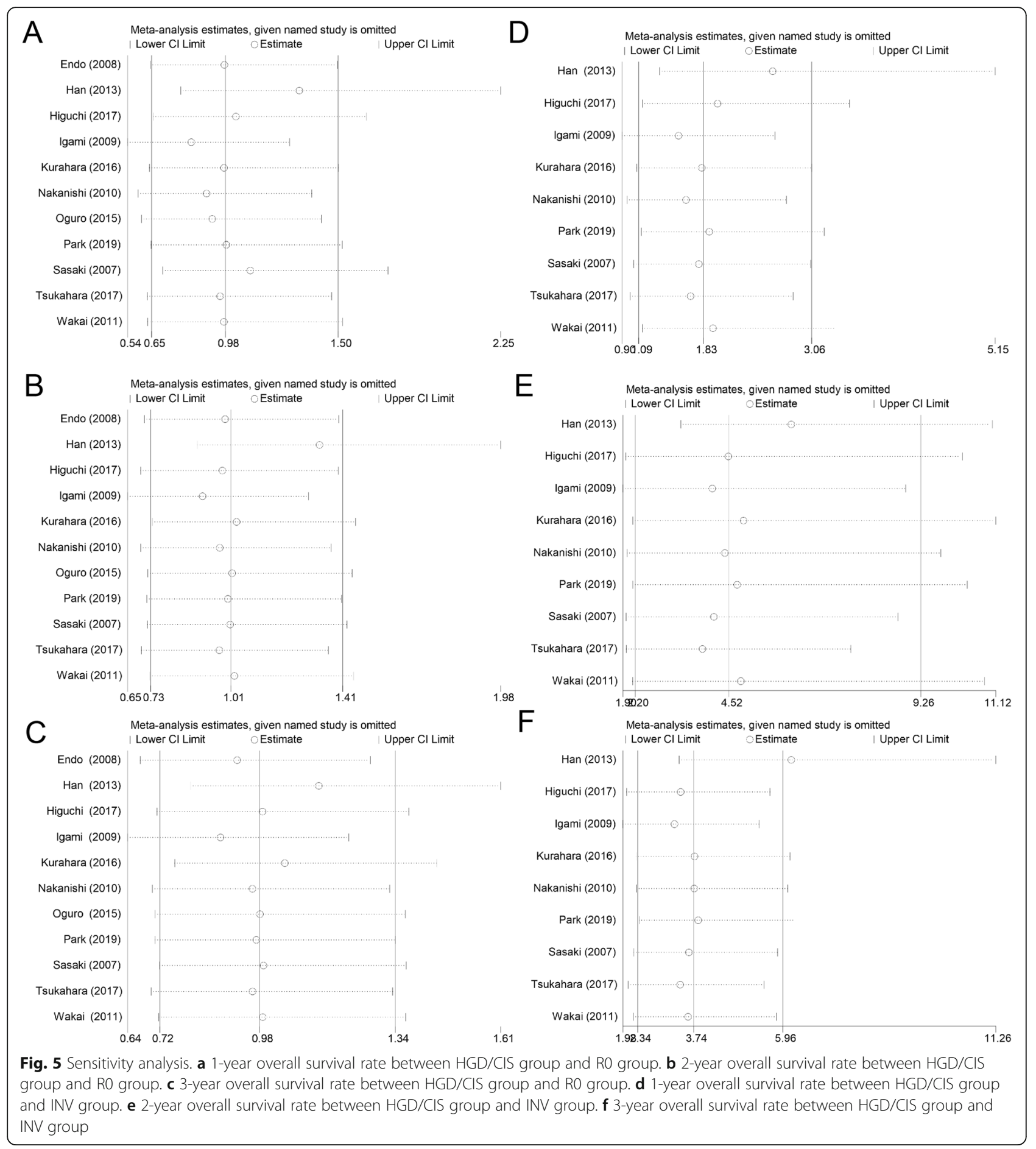

3.5 18.3\%, respectively. Results showed that the pooled ORs of 1-, 2-, and 3-year survival rates between HGD/ CIS group and R0 group were $0.98(P=0.94), 1.01(P=$ $0.793)$, and $0.98(P=0.91)$, but the pooled OR for the 1-, 2-, and 3-year survival rate between HGD/CIS group and INV group was $1.83(P=0.02), 4.52(P<0.0001)$, and 3.74 $(P<0.0001)$, respectively. In addition, the results did not change sustainably after sensitivity analysis.
Hence, HGD/CIS might not affect the prognosis of patients with extrahepatic cholangiocarcinoma, and the conclusion was reliable to some extent.

Tumor stage is usually the key factor for the treatment decision [4, 37]. Some argued that HGD/CIS affected the prognosis of patients with pNOM0 [17-19, 34], partly because the prognosis of patients at early stage might be more likely to be affected by the margin status 
Table 3 Baseline characteristics related to prognosis

\begin{tabular}{|c|c|c|c|c|}
\hline Outcome & Studies & Participants & Effect model & OR $(95 \% \mathrm{Cl})$ \\
\hline \multicolumn{5}{|l|}{ HGD/CIS vs. RO } \\
\hline Adjuvant therapy & 3 & 377 & Fixed & $1.55(0.75-3.20)$ \\
\hline Differentiation (moderate/poor) & 5 & 660 & Fixed & $0.62(0.36-1.06)$ \\
\hline Venous invasion & 3 & 389 & Fixed & $1.87(0.83-4.21)$ \\
\hline Perineural invasion & 4 & 575 & Fixed & $1.00(0.52-1.91)$ \\
\hline pT $3 / 4^{*}$ & 4 & 494 & Fixed & $0.57(0.29-1.10)$ \\
\hline $\mathrm{pN} 1 / 2^{*}$ & 3 & 388 & Fixed & $0.52(0.24-1.15)$ \\
\hline \multicolumn{5}{|l|}{ HGD/CIS vs. INV } \\
\hline Adjuvant therapy & 4 & 203 & Fixed & $0.79(0.42-1.47)$ \\
\hline Differentiation (moderate/poor) & 5 & 126 & Fixed & $0.50(0.23-1.08)$ \\
\hline Venous invasion & 3 & 76 & Random & $0.30(0.02-4.07)$ \\
\hline Perineural invasion & 4 & 95 & Fixed & $0.44(0.15-1.33)$ \\
\hline pT $3 / 4^{*}$ & 4 & 102 & Fixed & $0.44(0.19-1.02)$ \\
\hline $\mathrm{pN} 1 / 2^{*}$ & 3 & 73 & Fixed & $0.62(0.22-1.76)$ \\
\hline
\end{tabular}

${ }^{*}$ According to the 8th edition American Joint Committee on Cancer (AJCC) staging guidelines

than those at advanced stage. In this meta-analysis, subgroup analysis of extrahepatic cholangiocarcinoma at early stage was conducted. Results showed that the pooled OR for the 1-, 2-, and 3-year survival rate between HGD/CIS group and R0 group was 0.54 $(P=$ $0.19), 0.75(P=0.44)$, and $0.74(P=0.34)$, respectively, but the 1-, 2-, and 3-year survival rates of patients with pNOM0 comparing between HGD/CIS group and INV group were $3.47(P=0.03), 9.12(P<0.001)$, and $9.17(P$ $<0.001)$, respectively, which were coincident with the whole. This indicated that the conclusion that HGD/CIS might not affect the prognosis of patients with extrahepatic cholangiocarcinoma was suitable for the subgroup of early stage, but it should be cautious as for patients at advanced stage.

Recurrence is the Achilles' heel for hepatobiliary cancers, which is often the just arch-criminal for the poor prognosis $[4,42]$. The incidence of 2-year recurrence is reported to be as high as $80 \%[43,44]$, and the R1 is often considered to be one of the important factors for recurrence $[9,11]$. In this meta-analysis, local recurrence was taken as the secondary endpoint. Results showed that the pooled OR for the incidence of local recurrence between HGD/CIS group and R0 group was 3.54 ( $P=$ 0.001 ), and the pooled OR for the incidence of recurrence between HGD/CIS group and R0 group was 0.93 $(P=0.83)$, which indicated that additional resection should be recommended to achieve R0 if technically possible.

There were several restrictions of this meta-analysis. First, all the included studies were single-center and small sample, indicating an obvious selection bias. Second, 10 of 11 the included studies came from Japan and South Korea [12, 17-19, 30, 32-36], indicating an apparent regional bias because the epidemiology differed between the West and East. Third, the TNM staging systems and surgical procedures were greatly different between hilar cholangiocarcinoma and distal cholangiocarcinoma $[4,6,8]$, but most of the included studies had not treated them separately $[18,19,30,32-35]$. Fourth, the results of the intraoperative frozen section were unreliable because the margin was broken by energy instruments such as CUSA. Fifth, all the included studies were retrospective studies, indicating an apparent recalling bias, although the baseline characteristics were confirmed comparable both between HGD/CIS group and R0 group and between HGD/CIS group and INV group. The last but not the least, publication bias was hard to be avoided, although significant publication bias was not detected after "trim and fill" analysis.

\section{Conclusion}

With the current data, we concluded that HGD/CIS did not affect the prognosis of patients with extrahepatic cholangiocarcinoma regardless of TNM stage, but it increased the risk of local recurrence compared with $\mathrm{R} 0$. Hence, additional resection should be recommended if technically possible. In future, to distinguish HGD/CIS from INV is the crucial, and multi-center, larger sample, and prospective randomized trials are warranted to reach a definite conclusion.

\section{Abbreviations}

HGD: High-grade dysplasia; CIS: Carcinoma in situ; INV: Invasive carcinoma; HCCA: Hilar cholangiocarcinoma; PHC: Perihilar cholangiocarcinoma;

OS: Overall survival; OR: Odds ratio; Cl: Confidence interval; RCT: Randomized controlled trial

Acknowledgements

Not applicable 


\section{Authors' contributions}

QK, BW, and NPL contributed to acquisition, analysis, and interpretation of data; LW contributed to conception and design of the study, acquisition of data, analysis and interpretation of data, drafting the article, and final approval; and JFL contributed to critical revision and final approval. The other authors read and approved the final manuscript.

\section{Funding}

This study was supported by the Startup Fund for scientific research, Fujian Medical University (Grant number: 2018QH1195).

\section{Availability of data and materials}

All data generated or analyzed during this study are included in the published articles.

\section{Ethics approval and consent to participate}

Not applicable

\section{Consent for publication}

Not applicable

\section{Competing interests}

The authors declare that they have no competing interests.

\section{Author details}

'Department of Hepatopancreatobiliary Surgery, Mengchao Hepatobiliary Hospital of Fujian Medical University, Xihong Road 312, Fuzhou 350025, Fujian, China. ${ }^{2}$ Department of Pathology, School of Basic Medical Sciences of Fujian Medical University, Fuzhou, China. ' ${ }^{3}$ epartment of Pathology, Mengchao Hepatobiliary Hospital of Fujian Medical University, Fuzhou, China. ${ }^{4}$ Department of Radiation Oncology, Mengchao Hepatobiliary Hospital of Fujian Medical University, Fuzhou, China. ${ }^{5}$ Liver Disease Center, The First Affiliated Hospital of Fujian Medical University, Fuzhou, China.

\section{Received: 9 September 2019 Accepted: 14 November 2019}

\section{Published online: 09 December 2019}

\section{References}

1. Bray F, Ferlay J, Soerjomataram I, Siegel RL, Torre LA, Jemal A. Global cancer statistics 2018: GLOBOCAN estimates of incidence and mortality worldwide for 36 cancers in 185 countries. CA Cancer J Clin. 2018;68:394-424.

2. Van Dyke AL, Shiels MS, Jones GS, Pfeiffer RM, Petrick JL, Beebe-Dimmer $J$, Koshiol J. Biliary tract cancer incidence and trends in the United States by demographic group, 1999-2013. Cancer-Am Cancer Soc. 2019;125:1489-98.

3. Bertuccio P, Malvezzi M, Carioli G, Hashim D, Boffetta P, El-Serag HB, La Vecchia C, Negri E. Global trends in mortality from intrahepatic and extrahepatic cholangiocarcinoma. J Hepatol. 2019;71:104-14.

4. Benson AB, D'Angelica Ml, Abbott DE, Abrams TA, Alberts SR, Anaya DA, Anders R, Are C, Brown D, Chang DT, et al. Guidelines insights: hepatobiliary cancers, Version 2.2019. J Natl Compr Canc Netw. 2019;17:302-10.

5. Franken LC, Schreuder AM, Roos E, van Dieren S, Busch OR, Besselink MG, van Gulik TM. Morbidity and mortality after major liver resection in patients with perihilar cholangiocarcinoma: a systematic review and meta-analysis. Surgery. 2019;165:918-28.

6. Strijker M, Belkouz A, van der Geest LG, van Gulik TM, van Hooft JE, de Meijer VE, Haj MN, de Reuver PR, Verheij J, de Vos-Geelen J, et al. Treatment and survival of resected and unresected distal cholangiocarcinoma: a nationwide study. Acta Oncol. 2019;58:1048-55.

7. Esnaola NF, Meyer JE, Karachristos A, Maranki JL, Camp ER, Denlinger CS. Evaluation and management of intrahepatic and extrahepatic cholangiocarcinoma. Cancer-Am Cancer Soc. 2016;122:1349-69.

8. Cillo U, Fondevila C, Donadon M, Gringeri E, Mocchegiani F, Schlitt HJ, ljzermans J, Vivarelli M, Zieniewicz K, Olde DS, Groot KB. Surgery for cholangiocarcinoma. Liver Int. 2019;39(Suppl 1):143-55.

9. Hu HJ, Mao H, Shrestha A, Tan YQ, Ma WJ, Yang Q, Wang JK, Cheng NS, Li FY. Prognostic factors and long-term outcomes of hilar cholangiocarcinoma: a single-institution experience in China. World J Gastroenterol. 2016;22: 2601-10.

10. Bird N, McKenna A, Dodd J, Poston G, Jones R, Malik H. Meta-analysis of prognostic factors for overall survival in patients with resected hilar cholangiocarcinoma. Br J Surg. 2018;105:1408-16.
11. Chua TC, Mittal A, Arena J, Sheen A, Gill AJ, Samra JS. Resection margin influences survival after pancreatoduodenectomy for distal cholangiocarcinoma. Am J Surg. 2017;213:1072-6.

12. Park Y, Hwang DW, Kim JH, Hong SM, Jun SY, Lee JH, Song KB, Jun ES, Kim SC, Park KM. Prognostic comparison of the longitudinal margin status in distal bile duct cancer: RO on first bile duct resection versus $\mathrm{R} 0$ after additional resection. J Hepatobiliary Pancreat Sci. 2019;26:169-78.

13. Zhang XF, Squires MR, Bagante F, Ethun CG, Salem A, Weber SM, Tran T, Poultsides G, Son AY, Hatzaras I, et al. The impact of intraoperative reresection of a positive bile duct margin on clinical outcomes for hilar cholangiocarcinoma. Ann Surg Oncol. 2018;25:1140-9.

14. Lee J, Kang SH, Noh OK, Chun M, Oh YT, Kim BW, Kim SW. Adjuvant concurrent chemoradiation therapy in patients with microscopic residual tumor after curative resection for extrahepatic cholangiocarcinoma. Clin Transl Oncol. 2018;20:1011-7.

15. Messina C, Merz V, Frisinghelli M, Trentin C, Grego E, Veccia A, Salati M, Messina M, Carnaghi C, Caffo O. Adjuvant chemotherapy in resected bile duct cancer: a systematic review and meta-analysis of randomized trials. Crit Rev Oncol Hematol. 2019;143:124-9.

16. Wakai T, Sakata J, Katada T, Hirose Y, Soma D, Prasoon P, Miura K, Kobayashi T. Surgical management of carcinoma in situ at ductal resection margins in patients with extrahepatic cholangiocarcinoma. Ann Gastroenterol Surg. 2018;2:359-66.

17. Higuchi R, Yazawa T, Uemura S, Izumo W, Furukawa T, Yamamoto M. Highgrade dysplasia/carcinoma in situ of the bile duct margin in patients with surgically resected node-negative perihilar cholangiocarcinoma is associated with poor survival: a retrospective study. J Hepatobiliary Pancreat Sci. 2017; 24:456-65.

18. Kurahara H, Maemura K, Mataki Y, Sakoda M, lino S, Kawasaki Y, Mori S, Kijima $Y$, Ueno S, Shinchi $H$, et al. Relationship between the surgical margin status, prognosis, and recurrence in extrahepatic bile duct cancer patients. Langenbecks Arch Surg. 2017:402:87-93.

19. Tsukahara T, Ebata T, Shimoyama Y, Yokoyama Y, Igami T, Sugawara G, Mizuno T, Nagino M. Residual carcinoma in situ at the ductal stump has a negative survival effect: an analysis of early-stage cholangiocarcinomas. Ann Surg. 2017;266:126-32.

20. Shiraki T, Kuroda H, Takada A, Nakazato Y, Kubota K, Imai Y. Intraoperative frozen section diagnosis of bile duct margin for extrahepatic cholangiocarcinoma. World J Gastroenterol. 2018;24:1332-42.

21. Tierney JF, Stewart LA, Ghersi D, Burdett S, Sydes MR. Practical methods for incorporating summary time-to-event data into meta-analysis. Trials. 2007:8:16.

22. Parmar MK, Torri V, Stewart L. Extracting summary statistics to perform meta-analyses of the published literature for survival endpoints. Stat Med. 1998:17:2815-34.

23. Stang A. Critical evaluation of the Newcastle-Ottawa scale for the assessment of the quality of nonrandomized studies in meta-analyses. Eur J Epidemiol. 2010;25:603-5.

24. Deeks JJ, Altman DG: Chapter 9. Analysing data and undertaking metaanalyses. Cochrane handbook for systematic reviews of interventions Cochrane book 2011.

25. Higgins, JP: Measuring inconsistency in meta-analyses. BMJ 2003, 327:557-560.

26. Li MX, Bi XY, Li ZY, Huang Z, Han Y, Zhao JJ, Zhao H, Cai JQ. Impaction of surgical margin status on the survival outcome after surgical resection of intrahepatic cholangiocarcinoma: a systematic review and meta-analysis. J Surg Res. 2016;203:163-73.

27. Wakai T, Shirai Y, Moroda T, Yokoyama N, Hatakeyama K. Impact of ductal resection margin status on long-term survival in patients undergoing resection for extrahepatic cholangiocarcinoma. Cancer-Am Cancer Soc. 2005;103:1210-6.

28. Higuchi R, Ota T, Araida T, Kobayashi M, Furukawa T, Yamamoto M. Prognostic relevance of ductal margins in operative resection of bile duct cancer. Surgery. 2010;148:7-14.

29. Ueda J, Yoshida H, Mamada Y, Taniai N, Yoshioka M, Hirakata A, Kawano Y, Mizuguchi Y, Shimizu T, Kanda T, et al. Evaluation of positive ductal margins of biliary tract cancer in intraoperative histological examination. Oncol Lett. 2018;16:6677-84.

30. Sasaki R, Takeda Y, Funato O, Nitta H, Kawamura H, Uesugi N, Sugai T, Wakabayashi G, Ohkohchi N. Significance of ductal margin status in patients undergoing surgical resection for extrahepatic cholangiocarcinoma. World J Surg. 2007;31:1788-96 
31. Endo I, House MG, Klimstra DS, Gonen M, D'Angelica M, Dematteo RP, Fong Y, Blumgart LH, Jarnagin WR. Clinical significance of intraoperative bile duct margin assessment for hilar cholangiocarcinoma. Ann Surg Oncol. 2008;15: 2104-12.

32. Igami T, Nagino M, Oda K, Nishio H, Ebata T, Yokoyama Y, Shimoyama Y. Clinicopathologic study of cholangiocarcinoma with superficial spread. Ann Surg. 2009;249:296-302.

33. Nakanishi $\mathrm{Y}$, Kondo $\mathrm{S}$, Zen $\mathrm{Y}$, Yonemori A, Kubota K, Kawakami H, Tanaka E, Hirano S, Itoh T, Nakanuma Y. Impact of residual in situ carcinoma on postoperative survival in 125 patients with extrahepatic bile duct carcinoma. J Hepatobiliary Pancreat Sci. 2010;17:166-73.

34. Wakai T, Shirai Y, Sakata J, Korita PV, Matsuda Y, Takamura M, Ohashi R, Nagahashi M, Ajioka Y, Hatakeyama K. Alteration of p53-binding protein 1 expression as a risk factor for local recurrence in patients undergoing resection for extrahepatic cholangiocarcinoma. Int J Oncol. 2011;38:1227-36.

35. Han IW, Jang JY, Lee KB, Kang MJ, Kwon W, Park JW, Chang YR, Kim SW. Clinicopathological analysis and prognosis of extrahepatic bile duct cancer with a microscopic positive ductal margin. HPB (Oxford). 2014;16:575-81.

36. Oguro S, Esaki M, Kishi Y, Nara S, Shimada K, Ojima H, Kosuge T. Optimal indications for additional resection of the invasive cancer-positive proximal bile duct margin in cases of advanced perihilar cholangiocarcinoma. Ann Surg Oncol. 2015;22:1915-24.

37. Khan SA, Davidson BR, Goldin RD, Heaton N, Karani J, Pereira SP, Rosenberg WM, Tait P, Taylor-Robinson SD, Thillainayagam AV, et al. Guidelines for the diagnosis and treatment of cholangiocarcinoma: an update. Gut. 2012;61: 1657-69.

38. Buettner S, Margonis GA, Kim Y, Gani F, Ethun CG, Poultsides G, Tran T, Idrees $\mathrm{K}$, Isom CA, Fields RC, et al. Conditional probability of long-term survival after resection of hilar cholangiocarcinoma. HPB (Oxford). 2016;18: 510-7.

39. Mantel HT, Westerkamp AC, Sieders E, Peeters PM, de Jong KP, Boer MT, de Kleine RH, Gouw AS, Porte RJ. Intraoperative frozen section analysis of the proximal bile ducts in hilar cholangiocarcinoma is of limited value. Cancer Med. 2016;5:1373-80.

40. Ma WJ, Shrestha A, Li FY. Is intraoperative frozen section analysis of the proximal bile ducts in hilar cholangiocarcinoma of limited value? Cancer Med. 2016;5:2848-9.

41. Otsuka S, Ebata T, Yokoyama Y, Mizuno T, Tsukahara T, Shimoyama Y, Ando M, Nagino M. Clinical value of additional resection of a margin-positive distal bile duct in perihilar cholangiocarcinoma. Br J Surg. 2019;106:774-82.

42. Shroff RT, Kennedy EB, Bachini M, Bekaii-Saab T, Crane C, Edeline J, ElKhoueiry A, Feng M, Katz M, Primrose J, et al. Adjuvant therapy for resected biliary tract cancer: ASCO clinical practice guideline. J Clin Oncol. 2019;37: 1015-27.

43. Zhang XF, Beal EW, Chakedis J, Chen Q, Lv Y, Ethun CG, Salem A, Weber $S M$, Tran T, Poultsides G, et al. Defining early recurrence of hilar cholangiocarcinoma after curative-intent surgery: a multi-institutional study from the US Extrahepatic Biliary Malignancy Consortium. World J Surg. 2018; 42:2919-29.

44. Groot KB, Wiggers JK, Allen PJ, Besselink MG, Blumgart LH, Busch OR, Coelen RJ, D'Angelica MI, DeMatteo RP, Gouma DJ, et al. Recurrence rate and pattern of perihilar cholangiocarcinoma after curative intent resection. J Am Coll Surg. 2015;221:1041-9.

\section{Publisher's Note}

Springer Nature remains neutral with regard to jurisdictional claims in published maps and institutional affiliations.

Ready to submit your research? Choose BMC and benefit from:
- fast, convenient online submission
- thorough peer review by experienced researchers in your field
- rapid publication on acceptance
- support for research data, including large and complex data types
- gold Open Access which fosters wider collaboration and increased citations
- maximum visibility for your research: over 100M website views per year
At BMC, research is always in progress.
Learn more biomedcentral.com/submissions

